\title{
Temporal Changes In Revealed Migration Preferences
}

\author{
ROBERT E. LLOYD*
}

Migration patterns in the United States are a result of many individual decisions made by persons who may have considered many alternatives within the environment. Changes in migration patterns will occur over time for a number of reasons. Changes may occur in the characteristics of specific places which are being considered by the migrants, e.g., the number of employment opportunities may go down in one place or up in another place. Another determinant of migration patterns is the particular decision-making rules used by migrants to choose among the alternatives within the environment. Rushton has argued that these rules of spatial behavior are place independent, i.e., they are unlikely to vary significantly from one area to another unless a major cultural boundary is crossed. ${ }^{1}$ In a more general sense, it might be argued that the rules of spatial behavior are likely to change only if a major cultural change has occurred in space or time and, therefore, they are likely to change very slowly for a particular area. Rushton has made a distinction between the spatial patterns produced by behavior, which he called "behavior in space," and the rules used by decision-makers to evaluate the spatial opportunities, which he called "spatial behavior."" The purpose of this paper is to examine the proposition that, although migration behavior in space may change considerably over time, the rules of spatial behavior related to migration will change very little over time.

The temporal dimension, which is a major consideration of this research problem, places some limitations on the availability of suitable data. The United States Bureau of the Census has reported interstate migration flows since the 1940 census. ${ }^{3}$ Therefore, four sets of data are available at the state level which can serve as the basic information for migration behavior over a thirty year time period. The migration data form matrices which have origin states as rows and destination states as columns. Each element of the matrix contains the flow of migrants from origin state i to destination state j. Other types of data at a more micro scale, e.g., flows among urban neighborhoods, would be of interest because they are much closer to the individual decision-making level, but such data are very difficult to obtain for an extended time period. The state flow data are recognized as being extremely gross, but they are thought to be sufficient to answer three basic questions:

*The University of South Carolina. 
1. Do the migration flows indicate that the distribution of migrants from origin states to destination states has changed over time, i.e., has behavior in space changed over time?

2. Have there been any changes in the relationships which migration behavior in space has with selected characteristics of states, i.e., population size and distance?

3. Has spatial behavior, i.e., the rules used by migrants to evaluate spatial opportunities, changed over time?

\section{The Distribution of Migrants from Origins to Destinations}

If each row element in a particular flow matrix is divided by the row sum, then the raw flow is converted to the probability of the origin state $\mathrm{i}$ sending a migrant to destination state $\mathrm{j}$ during time period $\mathrm{k}$. The variation of each origin state's distribution of migrants to the destination states can then be summarized using a simple entropy index: ${ }^{4}$

$$
\begin{aligned}
\mathrm{H}_{\mathrm{ik}} & =-\sum_{\mathrm{j}=1}^{\mathrm{n}} \mathrm{P}_{\mathrm{ijk}} \log _{2}\left(\mathrm{P}_{\mathrm{ijk}}\right) \\
\mathrm{H}_{\mathrm{ik}}= & \text { the entropy index of origin state } \mathrm{i} \text { for time } \mathrm{k} \\
\mathrm{P}_{\mathrm{ijk}}= & \text { the probability of origin state } \mathrm{i} \text { sending a } \\
\mathrm{n} & \text { migrant to destination } \mathrm{j} \text { during time } \mathrm{k}
\end{aligned}
$$

The entropy index will have a minimum value of 0.0 when all the migrants from an origin state go to the same destination state, and a maximum value of 5.58 , for $n=48$, if each destination state receives $1 / \mathrm{nth}$ of the origin states migrants. Where a migrant will go can easily be predicted for the minimum entropy case because they always go to the same destination. Where a migrant will go cannot be easily predicted for the minimum entropy case because every state is an equally likely destination. A comparison of the entropy indices at the beginning and end of the thirty year period indicates that every state had a higher index value in 1970 than it did in 1940 with the average state increasing from an index value of 2.46 to 3.29 (Table I).

The set of entropy indices must be considered as measures of behavior in space, rather than spatial behavior, since the behavior is relative to a particular set of environmental units. The entropy indices suggest that migration behavior in space has changed over time for each origin state. They also indicate that the change was consistent among the states in at least one respect-the states have all moved toward a maximum entropy situation, i.e., toward a more random distribution of migrants to destination states. If this trend continues, it should become more and more difficult to understand the migration process using methods that consider only behavior in space, because the migration behavior relative to the specific set of environmental units will appear to be random. 
TABLE I.-Entropy indices for origin states for specific time periods

\begin{tabular}{|c|c|c|c|c|c|c|c|c|c|}
\hline State & 1940 & 1950 & 1960 & 1970 & State & 1940 & 1950 & 1960 & 1970 \\
\hline Maine & 2.39 & 3.40 & 3.66 & 3.77 & South Carolina & 2.33 & 2.87 & 3.52 & 3.66 \\
\hline New Hampshire & 3.17 & 2.96 & 3.72 & 3.92 & Georgia & 2.14 & 2.44 & 3.02 & 3.11 \\
\hline Vermont & 2.58 & 3.46 & 3.59 & 3.67 & Florida & 2.67 & 3.56 & 3.65 & 3.83 \\
\hline Massachusetts & 2.31 & 3.44 & 3.41 & 3.53 & Kentucky & 2.75 & 3.08 & 3.48 & 3.48 \\
\hline Rhode Island & 2.68 & 3.80 & 3.90 & 4.03 & Tennessee & 3.03 & 3.30 & 3.83 & 3.76 \\
\hline Connecticut & 2.56 & 3.96 & 3.73 & 3.97 & Alabama & 2.62 & 2.82 & 3.39 & 3.64 \\
\hline New York & 2.78 & 2.76 & 2.62 & 2.82 & Mississippi & 2.21 & 2.67 & 3.36 & 3.61 \\
\hline New Jersey & 2.08 & 3.19 & 3.90 & 3.33 & rkansas & 3.12 & 3.18 & 3.56 & 3.50 \\
\hline Pennsylvania & 2.66 & 3.16 & 3.21 & 3.38 & Louisiana & 2.33 & 2.71 & 2.84 & 3.09 \\
\hline Ohio & 2.42 & 3.09 & 3.25 & 3.35 & Oklahoma & 2.85 & 2.82 & 3.27 & 3.27 \\
\hline Indiana & 2.42 & 3.03 & 3.34 & 3.36 & Texas & 1.75 & 2.28 & 2.79 & 2.78 \\
\hline Illinois & 3.06 & 3.65 & 3.64 & 3.75 & Montana & 2.92 & 3.19 & 3.33 & 3.68 \\
\hline Michigan & 1.99 & 2.84 & 3.02 & 2.85 & Idaho & 2.82 & 3.05 & 3.25 & 3.48 \\
\hline Wisconsin & 2.42 & 2.70 & 3.86 & 2.96 & yoming & 3.77 & 4.04 & 4.04 & 4.12 \\
\hline Minnesota & 2.61 & 2.75 & 2.85 & 2.84 & Colorado & 3.09 & 3.30 & 3.40 & 3.59 \\
\hline Iowa & 2.76 & 2.76 & 3.18 & 3.28 & New Mexico & 3.02 & 3.37 & 3.69 & 3.96 \\
\hline Missouri & 2.84 & 3.18 & 3.06 & 3.26 & Arizona & 2.86 & 3.96 & 3.62 & 3.99 \\
\hline North Dakota & 3.26 & 2.98 & 3.31 & 3.78 & Utah & 2.76 & 3.24 & 3.22 & 3.69 \\
\hline South Dakota & 3.42 & 3.13 & 3.56 & 3.74 & Nevada & 2.91 & 3.51 & 3.63 & 3.98 \\
\hline Nebraska & 3.32 & 3.15 & 3.55 & 3.64 & Washington & 2.11 & 3.16 & 3.09 & 3.14 \\
\hline Kansas & 3.23 & 3.26 & 3.65 & 3.47 & Oregon & 2.11 & 2.67 & 2.61 & 2.74 \\
\hline Delaware & 2.79 & 4.23 & 4.30 & 3.06 & California & 1.73 & 2.97 & 2.60 & 3.02 \\
\hline Maryland & 3.15 & 3.52 & 3.35 & 3.51 & & & & & \\
\hline Virginia & 2.84 & 3.23 & 3.29 & 3.42 & Average & 2.46 & 3.00 & 3.16 & 3.29 \\
\hline West Virginia & 2.66 & 2.94 & 3.48 & 3.60 & Minimum & 0.00 & 0.00 & 0.00 & 0.00 \\
\hline North Carolina & 2.08 & 2.57 & 3.18 & 3.30 & Maximum & 5.58 & 5.58 & 5.58 & 5.58 \\
\hline
\end{tabular}

\section{Migration Behavior's Relationship to Selected Characteristics of Destination States}

Another way of understanding behavior in space is to express the behavior's covariation with specific characteristics of the environmental units. Although many variables that could covary with migration might be considered, for the sake of simplicity, two variables known to be related to migration flows were selected. ${ }^{5}$ Regression models were calibrated for the four time periods using the migration flows as the dependent variable and the population of the destination states and distance between the origin and destination state as the independent variables. ${ }^{6}$ This gravity model type of analysis should indicate if migration behavior in space has changed relative to these two simple characteristics of the environment (Table II). It should be noted that, although the multiple correlation coefficients for the four models are essentially the same $(r$ values ranging from 0.694 to 0.725 ), the relative importance of population and distance as predictors of migration has changed over time. The relative importance of the two independent variables was indexed by making a ratio of their beta weights (Table II). Comparing these ratios over time suggests that population is becoming a more important predictor of migration behavior while distance is becoming less important. The above 
regression analyses supply additional evidence that migration behavior in space has changed over time, but they cannot serve as evidence to determine if the rules of spatial behavior used by migrants have changed over time.

\section{Revealed Preferences and Spatial Behavior}

One might consider migrants as consumers, who, after considering the spatial opportunities available to them, select the most attractive location, and vote with their feet. If the spatial opportunities are classified according to some relevant criteria, then the relative preferences of the migrants for these classes of places will be revealed by the structure of the aggregate voting. This type of methodology is referred to as revealed preference analysis since preferences for locational types are revealed by the behavior of the individual decision-makers. ${ }^{7}$ The relative size of a destination state and the relative distance between origin and destination states were selected as potentially relevant characteristics of spatial opportunities that could be related to the migration decision. ${ }^{8}$ Although other characteristics might prove useful for a more complete understanding of the migration process, these two characteristics were selected so that the analysis might be kept relatively simple and so the results of the revealed preference analysis could be compared to the gravity model results (Table II).

The goal of the revealed preference analysis is to identify the relative preferences that migrants have for types of locations rather than their preferences for specific locations. A total of 36 locational types were defined using the following procedure. A six by six matrix was formed which classified destination states according to relative population size along the vertical axis and according to relative distance from origin states along the horizontal axis (Fig. 1). The rank order of population and distance were used, rather than actual population and distance, because actual population sizes have changed considerably over the 30 year time period. If the locational types were defined in terms of actual population size, it would be very difficult to make them directly comparable for the four time periods. Each cell in the matrix represents eight levels (ranks) of population size and eight levels (ranks) of distance and,

TABLE II.-Regressions of migration with population and distance for the four periods

\begin{tabular}{|c|c|c|c|c|c|c|}
\hline \multirow{2}{*}{$\begin{array}{l}\text { Time } \\
\text { Period }\end{array}$} & \multicolumn{2}{|c|}{ Population } & \multicolumn{2}{|c|}{ Distance } & \multirow{2}{*}{$\begin{array}{l}\text { Ratio of the } \\
\text { beta weightsa }\end{array}$} & \multirow{2}{*}{$\underset{\mathbf{R}}{\text { Multiple }}$} \\
\hline & b & beta & b & beta & & \\
\hline 1940 & 0.699 & 0.338 & -1.663 & -0.592 & 0.571 & 0.718 \\
\hline 1950 & 0.685 & 0.371 & -1.355 & -0.546 & 0.679 & 0.694 \\
\hline 1960 & 0.747 & 0.432 & -1.254 & -0.543 & 0.796 & 0.725 \\
\hline 1970 & 0.727 & 0.437 & -1.191 & -0.536 & 0.815 & 0.719 \\
\hline
\end{tabular}

aRatios are the absolute values of the population beta weight divided by the distance beta weight. 


\begin{tabular}{|c|c|c|c|c|c|c|}
\hline \multicolumn{7}{|c|}{$\begin{array}{l}\text { LOCATIONAL IYPES FOR THE } \\
\text { REVEALED MIGRATION PREFERENCES }\end{array}$} \\
\hline $41-48$ & 31 & 32 & 33 & 34 & 35 & 36 \\
\hline $33-40$ & 25 & 26 & 27 & 28 & 29 & 30 \\
\hline $25-32$ & 19 & 20 & 21 & 22 & 23 & 24 \\
\hline $17-24$ & 13 & 14 & 15 & 16 & 17 & 18 \\
\hline $9-16$ & 7 & 8 & 9 & 10 & 11 & 12 \\
\hline $1-8$ & 1 & 2 & 3 & 4 & 5 & 6 \\
\hline RELATIVELY SMAL & $\begin{array}{l}1-8 \\
Y \text { PEA }\end{array}$ & ${ }^{9-}$ & $17-26$ & $25-32$ & 40 & $\begin{aligned} 41-48 \\
\text { REL }\end{aligned}$ \\
\hline
\end{tabular}

Fig. 1. The 36 locational types defined by the rank order of population and distance. Each locational type is related to 64 individual migration flows, e.g., locational type 14 is related to the flows to destination states ranked 17 th to 24 th in population size from origin states that are the 9th to 16th distance rank from each of them.

therefore, each cell is related to 64 individual migration flows. For example, locational type one represents the migration flows to the eight smallest states from the eight states that are the shortest distances from them, and locational type 36 represents the migration flows to the eight largest states from the eight states that are the longest distances from them. The total number of migrants associated with each locational type were calculated from the flow matrices for each time period and used to develop preference scales. The degree to which one locational type was selected (preferred) over another by the migrants was computed using Rushton's paired comparison procedure and a preference index was computed from these dissimilarity estimates, for each time period, using multidimensional scaling. ${ }^{9}$

The preference indices for the four time periods were plotted in their respective classification spaces, and lines of equal preference were drawn to illustrate the trade-offs being made between relative population size and relative distance, i.e., all the locations along the length of a line are equally preferred (Fig. 2). The configurations of isolines seem to be very similar for the four time periods. The most preferred locational types were always in the upper left corner of the classification space, indicating that larger and closer locations were consistently preferred by the migrants. The least preferred location types were always in the lower right corner of the classification space, indicating that smaller and far away locations were consistently the migrant's least preferred choices. An interesting contrast among the spaces is that the isolines for the earlier 
time periods tend to be more vertical for choices made for the smaller distances. This indicates an increasing propensity for migrants to substitute states with larger populations at a farther distance, for states with smaller populations at a shorter distance. This change in the trade-offs between population and distance was examined more closely by subtracting the 1940 index values from the 1970 index values and plotting the differences in a classification space (Fig. 3). Location types relating to smaller populations and intermediate distances appear to be less preferred over time and locational types related to the next to the highest population category and farther distances appear to be more preferred over time.

REVEALED MIGRATION PREFERENCES
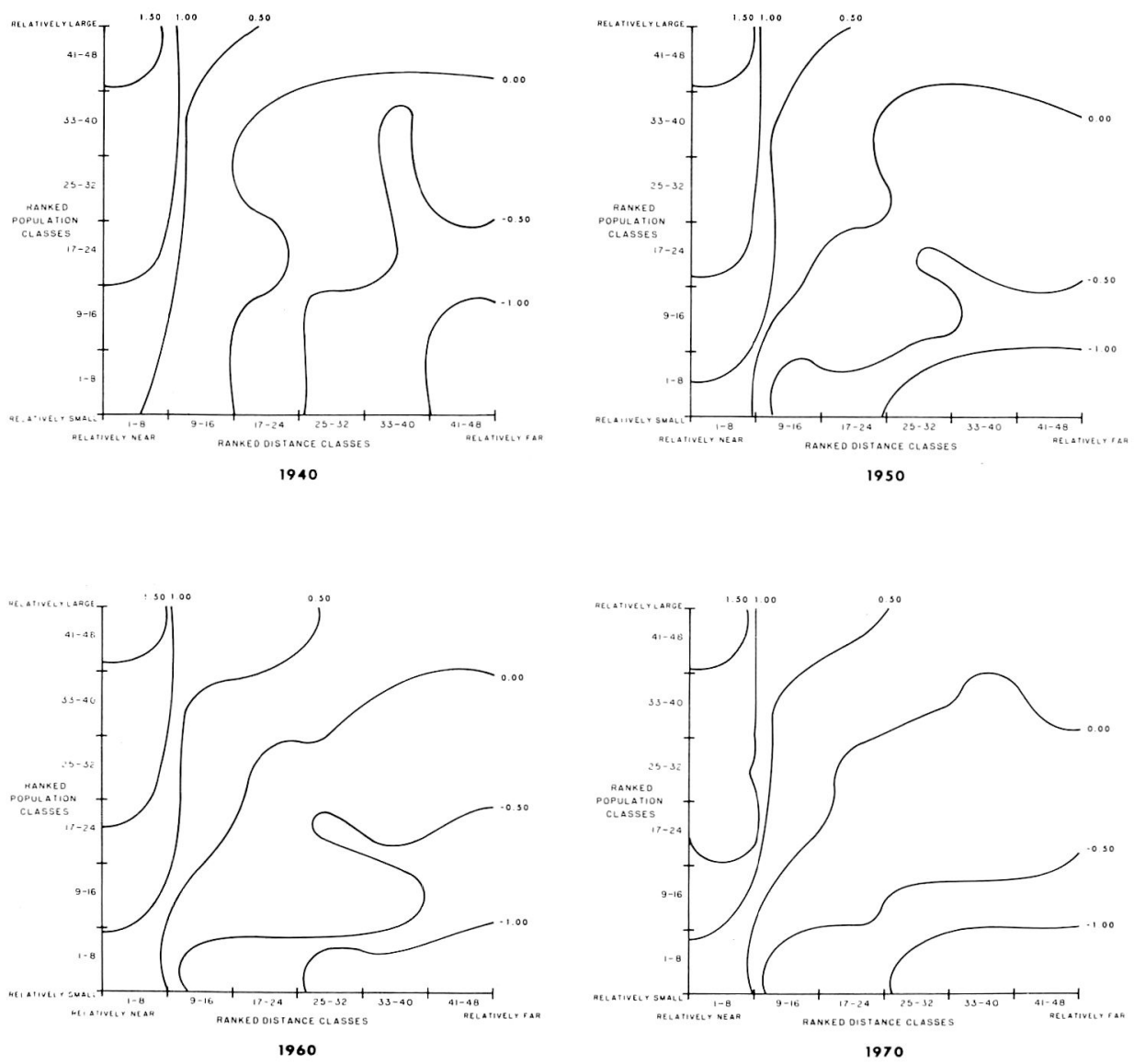

Fig. 2. The revealed migration preference spaces based on the 1940, 1950, 1960, and 1970 data. The indifference curves are lines of equal migration preference. 
Since the revealed preference spaces for the four time periods appear to be very similar and, at the same time, show a noticeable difference, an attempt was made to statistically isolate the basic pattern in the spaces from the changes, so their relative importance might be assessed. A canonical trend surface was performed using the locational type's index values for the four time periods as the criterion matrix and the linear and quadratic spatial coordinates of the locational types in the classification spaces as the predictor matrix..$^{10}$

The results indicate that two significant spatial patterns exist within the set of classification spaces, i.e., there are two significant canonical correlation coefficients $(0.97$ and 0.85 in Table III). The first canonical variable reflected the overall similarity of the distribution of the revealed preference index values in the 4 classification spaces. The canonical loadings range from 0.97 for the 1940 data to 0.99 for the 1970 data. The canonical scores for the first canonical variable were plotted in a classification space (Fig. 4). Their distribution within the classification space, which was very similar to the configurations for the four time periods, confirmed the contention that the first canonical variable represents the basic similarity of the original revealed preference spaces. The second canonical variable reflected the changes that have occurred over time with canonical loadings ranging from -0.22 for the 1940 data to 0.16 for the 1970 data. The canonical scores for the second canonical variable were also plotted in a classification space and their distribution, which is similar to the distribution of the differences between the 1970 and 1940 revealed preference index values (Fig. 3), support the contention that the second canonical variable represents the basic changes in the revealed

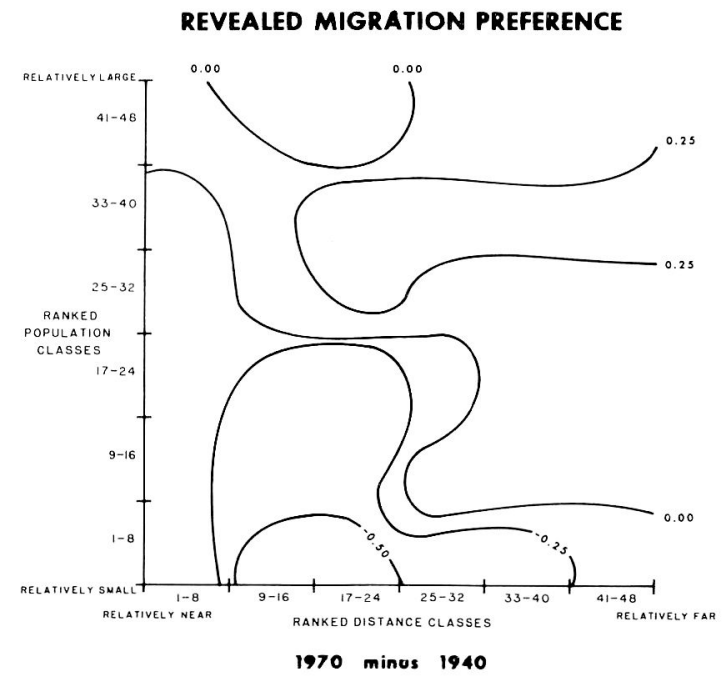

Fig. 3. Changes in the revealed migration preference spaces between 1940 and 1970. The isolines are lines of equal change in migration preference. 
TABLE III.-Summary of the canonical trend surface results using the locational type's revealed preference index values as the criterion matrix and the linear and quadratic spatial coordinates of the locational types as the predictor matrix

\begin{tabular}{|c|c|c|c|c|c|c|c|c|c|}
\hline $\begin{array}{l}\text { Canonical } \\
\text { Variable }\end{array}$ & $\begin{array}{r}\mathrm{C} \\
1940\end{array}$ & $\begin{array}{l}\text { nonical } \\
\text { r Time } \\
1950\end{array}$ & $\begin{array}{l}\text { Loadir } \\
\text { Perio } \\
1960\end{array}$ & $\begin{array}{l}\text { gs } \\
\text { s } \\
1970\end{array}$ & $\begin{array}{l}\text { Sum of } \\
\text { Squared } \\
\text { Loadings }\end{array}$ & $\begin{array}{l}\text { Canonical } \\
\text { Correlation }\end{array}$ & $\begin{array}{l}\text { Chi- } \\
\text { Square }\end{array}$ & D.F. & $\begin{array}{l}\text { Signif- } \\
\text { icance }\end{array}$ \\
\hline 1 & 0.97 & 0.97 & 0.98 & 0.99 & 3.82 & 0.97 & 141.8 & 20 & $\overline{0.0001}$ \\
\hline 2 & -0.22 & 0.11 & 0.07 & 0.16 & 0.09 & 0.85 & 52.0 & 12 & 0.0001 \\
\hline
\end{tabular}

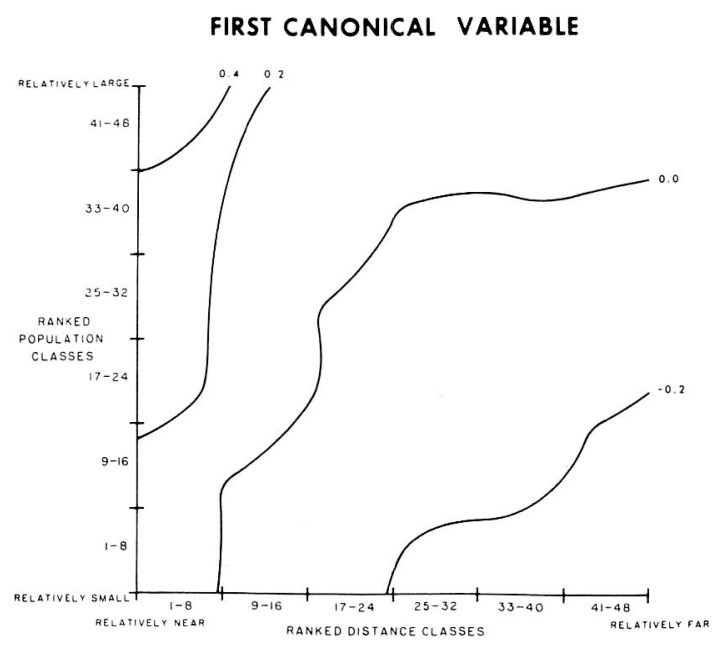

SECOND CANONICAL VARIABLE

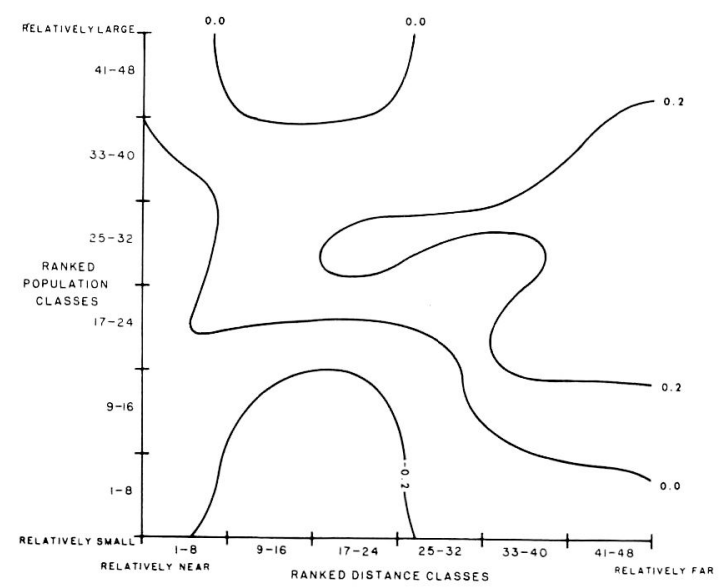

Fig. 4. Isoline plots of the statistically significant canonical variable scores from the canonical trend surface analysis of the four revealed preference spaces. The first canonical variable relates to the overall similarity of the four spaces and the second canonical variable relates to changes in the four spaces which have occurred over time. 
preference spaces that have occurred over time (Fig. 4). Although the chi-square tests indicate that neither of the canonical correlations is likely to have occurred by chance, the sum of the squared canonical loadings indicate that the basic similarity of the four revealed preference spaces accounts for much more of the total variance within the 4 spaces than is accounted for by changes occurring over time (95.5\% as opposed to $2.25 \%)$.

\section{Conclusions}

Migration behavior in space appears to have changed over time for the interstate flows within the United States. The entropy indices for the flows indicate that every state has a more uniform distribution of migrants to destination states in 1970 than it did in 1940. Changes in the migration flows might be explained in terms of changes in the environmental units or in terms of changes in the decision-making process of the migrants. If the perceived characteristics of the states remain exactly the same and the decision-making rules used by the migrants change, then the migration flows would change over time. If the perceived characteristics of the states change over time and the decision-making rules used by the migrants remain exactly the same, then the migration flows would also change over time. However, if the rules of spatial behavior being used by migrants are known, then migration flows can not only be predicted for a given environment, but can also be predicted for a changing environment. Gravity model calibrations indicate that the functional relationships between migration flows from origin states and the population sizes and distances of destination states have changed over time (Table II). The changes in the gravity model calibrations, however, do not necessarily reflect a change in the decision-making process of the migrants. They may merely relate to changes that have occurred within the environment. ${ }^{11}$

The revealed preference analyses, since they are not a function of specific environmental units, give a better indication of the changes which have occurred in the decision-making process of the migrants. These analyses indicate that the decision-making rules related to trade-offs between relative population size and relative distances are very similar over time. Although some statistically significant temporal changes were found in the migrant's relative trade-offs of population size and distance, they were minor compared to the overall similarity of the revealed preferences (Table III). Since migration decisions are such a complex process and only two of the many variables related to migration were considered, a complete understanding of migration behavior in space and spatial behavior will require further analysis. These results, however, do support the contention that the rules of spatial behavior, since they are independent of a particular environmental system, remain relatively constant over time. A better understanding of migration behavior requires a more complete understanding of these rules. 


\section{FOOTNOTES}

1 For a cross-cultural comparison of the rules of spatial behavior related to food shopping see Barry Lentnek, Stanley R. Leiber, and Ira Sheskin, "Consumer Behavior in Different Areas," Annals, The Association of American Geographers, Vol. 65, 1975, pp. 538-545.

2Gerard Rushton, "Analysis of Spatial Behavior by Revealed Space Preference," Annals, The Association of American Geographers, Vol. 59, 1969, pp. 391-400.

3 The data considered for the four time periods were the interstate flows among the 48 contiguous states. Migrants changing counties but remaining in the same state were included in the diagonal of the matrices. Alaska and Hawaii were excluded from the analysis because they were not states during the earlier time periods and flow data were not reported. Washington, D.C. was excluded from the analysis because internal migration figures were not available.

${ }_{4}^{4}$ For a discussion of the use of entropy indices to analyze migration flows see Y. Mdevedkov, "Entropy: An Assessment of Potentialities in Geography," Economic Geography, Vol. 46, Supplement, 1970, pp. 306-316.

5R. Paul Shaw, Migration Theory and Fact (Regional Science Research Institute, Philadelphia, 1975).

6 For all variables and all time periods a logarithmic transformation of the original variables was used.

${ }^{7}$ Gerard Rushton, "The Scaling of Locational Preferences," in K. Cox and R. Golledge (Eds.), Problems of Spatial Behavior: A Symposium (Northwestern University Studies in Geography Number 17, Evanston, 1969), pp. 197-227.

8 Most revealed preference studies relating to consumer behavior have used population size and distance to define locational types, Lentnek et al., op. cit. [see footnote 1 above], $p$. 540. The only exception known to the author is a study by Lieber. He used number of bowling lanes and distance to define locational types for his investigation of the spatial decision-making process of bowlers, Stanley $R$. Lieber, "Attitudes and Revealed Behavior: A Case Study," The Professional Geographer, Vol. 29, 1977, pp. 53-58.

9 Reginald Golledge and Gerard Rushton, Multidimensional Scaling: Review and Geographic Applications, Commission on College Geography Technical Paper No. 10 (Association of American Geographers, Washington, D.C., 1972).

10P. J. Lee, "The Theory and Application of Canonical Trend Surfaces," Journal of Geology, Vol. 77, 1969, pp. 303-318; and Mark S. Monmonier, "A Spatially-Controlled Principal Components Analysis," Geographical Analysis, Vol. 2, 1970, pp. 192-195.

${ }_{11 \mathrm{~A}}$ number of recent studies have challenged the reliability of regression coefficients related to gravity models. For a discussion of this issue see L. Curry, "A Spatial Analysis of Gravity Flow," Regional Studies, Vol. 6, 1972 , pp. 131-147; A. D. Cliff, R. L. Martin, and J. K. Ord, "Evaluating the Friction of Distance Parameter in Gravity Models," Regional Studies, Vol. 8, 1974, pp. 281-286; L. Curry, D. A. Griffith, and E. S. Sheppard, "Those Gravity Parameters Again," Regional Studies, Vol. 9, 1975, pp. 289-296; A. D. Cliff, R. L. Martin, and J. K. Ord, "Map Pattern and Friction of Distance Parameters: Reply to Comments by R. J. Johnston, and by L. Curry, D. A. Griffith, and E. S. Sheppard," Regional Studies, Vol. 9, 1975, pp. 285-288; E. S. Sheppard, D. A. Griffith, and L. Curry, "A Final Comment on Mis-Specification and Auto-correlation in those Gravity Parameters," Regional Studies, Vol. 10, 1976, pp. 337-339; and A. D. Cliff, R. L. Martin, and J. K. Ord, "A Reply to the Final Comment," Regional Studies, Vol. 10, 1976, pp. 341-342. 